\title{
New surveillance guidelines for Li-Fraumeni and hereditary TP53 related cancer syndrome: implications for germline TP53 testing in breast cancer
}

\author{
D. Gareth Evans ${ }^{1} \cdot$ Emma R. Woodward ${ }^{1}$
}

Published online: 28 September 2020

(c) Springer Nature B.V. 2020

Keywords Breast cancer $\cdot$ Heritable TP53-related cancer $\cdot$ Li-fraumeni syndrome $\cdot$ Penetrance $\cdot$ TP53 Sarcoma $\cdot$ Variant . MRI

$\begin{array}{ll}\text { Abbreviations } \\ \text { ACC } & \text { Adrenocortical carcinoma } \\ \text { ACMG } & \begin{array}{l}\text { American College of Medical Genetics and } \\ \text { Genomics }\end{array} \\ \text { AMP } & \text { Association for Molecular Pathology } \\ \text { CNS } & \text { Central nervous system } \\ \text { ERN } & \text { European reference network } \\ \text { GBCA } & \text { Gadolinium based contrast agents } \\ \text { HCP } & \text { Heath care professional } \\ \text { hTP53rc } & \text { Heritable TP53-related cancer } \\ \text { LFS } & \text { Li-Fraumeni syndrome } \\ \text { STS } & \text { Soft-tissue sarcoma } \\ \text { WBMRI } & \text { Whole }\end{array}$

\section{Introduction}

Heterozygous pathogenic germline variants were identified in TP53 in 1990 as a cause of Li-Fraumeni syndrome (LFS) [1]. LFS was originally labelled SBLA syndrome to reflect the predominance of Sarcoma, Breast/Brain, Leukaemia/ Lung cancer and Adrenal carcinoma in the original families [2, 3]. LFS is typically characterized by familial aggregations of very early-onset malignancies covering many tumour sites. These include the characteristic core LFS tumours: soft-tissue sarcomas (STS), osteosarcomas (OS), adrenocortical carcinomas (ACC), central nervous system

D. Gareth Evans

gareth.evans@mft.nhs.uk

1 Division of Evolution and Genomic Sciences, Manchester Centre for Genomic Medicine, University of Manchester, Manchester Academic Health Sciences Centre (MAHSC), St Mary's Hospital, Manchester University Hospitals NHS Foundation Trust, Manchester, UK
(CNS) tumours and very early-onset female breast cancers, typically occurring $\leq 30$ years. Germline testing for variants in TP53 has been most frequently employed in individuals with core LFS malignancies who fulfil clinical criteria such as classical LFS or "Chompret criteria" (Table 1a/b) [4, 5]. Nevertheless testing for individual tumours without a family history has been carried out in childhood malignancy [6-8] or among adult females with extremely early-onset breast cancers with germline TP53 mutations being identified in apparently isolated cases [5, 9]. Such findings have led to the idea being posited that a heritable TP53-related cancer (hTP53rc) syndrome would be a better term than LFS [10, 11]. Very recently two Europe based guidelines for surveillance in hTP53rc syndrome that include intensive surveillance with annual whole body MRI (WBMRI), brain MRI, breast MRI in women from age 20 years and blood testing (for ACC hormones) have been published [12, 13], to add to an American guideline [14]. The guidelines are based around the so-called 'Toronto' protocol that has been associated with a reported survival advantage [15]. The introduction of these intensive surveillance programmes, together with the increased availability of cancer predisposition gene testing, means it is particularly timely to understand both accurate variant interpretation and the clinical features where a genuinely pathogenic germline TP53 mutation is likely to be present.

\section{Likelihood of identifying a germline TP53 variant in breast cancer patients}

A review suggested that between $3.8-7.7 \%$ of women with breast carcinoma aged $\leq 30$ harboured pathogenic TP53 variants [16]. However, lower rates have since been reported at $2.2 \%$ in 370 Dutch women [17]. Nevertheless these data 
Table 1 Clinical diagnostic criteria for Li Fraumeni syndrome and TP53 testing

\begin{tabular}{lll}
\hline Criteria & Description & Reference \\
\hline (A) Classic & Proband diagnosed with a sarcoma before age 45 AND; One & [4] \\
& first-degree relative with any malignant tumour diagnosed \\
& before age 45 AND; Another first- or second-degree rela- \\
& tive diagnosed with any malignant tumour before age 45 or \\
& a sarcoma at any age \\
& Proband with a typical LFS tumor diagnosed before age 46 \\
& AND; At least one first- or second-degree relative diag- \\
& nosed with a typical LFS tumor (except breast cancer if the \\
& proband is/was affected by breast cancer) before age 56 or \\
& with multiple primary tumours OR; Proband with multiple \\
& primary tumours (other than multiple breast tumors) - \\
& including at least two from LFS tumor spectrum - with the \\
& first diagnosed before age 46 OR; Proband diagnosed with \\
& ADR or CPC , or RMS of embryonal anaplastic subtype* \\
& at any age irrespective of family history; OR \\
& Female proband with breast cancer < 31* \\
\hline
\end{tabular}

$C N S$ central-nervous system tumors, $A D R$ adrenocortical carcinoma, $C P C$ choroid-plexus carcinoma, $R M S$ rhabdomyosarcoma

*Added in modified Chompret criteria[8] have shown that a family history of cancer is not a pre-requisite when considering genetic testing of TP53. As early reports showed that the likelihood of germline TP53 reduced sharply after 30 years [18] and that germline TP53 only very rarely caused familial breast cancer unexplained by $B R C A I$ or BRCA2 [19], testing outside this extremely early onset group was rarely undertaken until recently unless the woman with breast cancer's personal or family history fulfilled at least Chompret/modified Chompret criteria [5]. Nonetheless, very low rates of germline TP53 mutation detected in breast cancer $>30$ years has recently been confirmed from the BRIDGES study of 60,466 cases and 53,461 controls [20]. In this study $4 / 346$ had truncating TP53 variants $<30$ years compared to $2 / 53,461$ controls $(\mathrm{OR}=309)$ compared to only $3 / 60,120(\mathrm{OR}=1.33)>30$ years $($ Easton D-personal communication).

The development of multi-gene cancer panels has resulted in much more widespread testing of TP53, as it is included in many commercial gene panels offered for germline cancer gene testing in breast cancer, the most frequent indication for commercial panel testing. For instance Ambry genetics provide an online tool [21] that can be interrogated. From this 79,368 women with breast cancer have been tested and the prevalence of pathogenic TP53 variants was $0.3 \%$ (https ://www.ambrygen.com/providers/resources/prevalence-tool, accessed 29th August 2020). Aged $\leq 30$ years this was 2.5\% in 2033 cases compared to $0.18 \%$ in $42197>46$ years. We do not know, however, whether there was pre-testing of those with LFS criteria to reduce the rates in those $\leq 30$ or whether some at $>46$ had elements of Chompret criteria. Testing in Manchester has found of 381 female breast cancers $\leq 30, T P 53$ was found in $22(5.80 \%)$, whereas of 921 women $>46$ only $2(0.22 \%)$ had TP53 with one having clear
LFS criteria reducing those $>46$ to only $0.11 \%$ without LFS criteria $(P<0.0001)$. The frequency in women aged $31-46$ was still only $0.33 \%(n=27623)$ using the Ambry tool.

\section{Breast cancer gene panel testing and the need for a refined approach}

The inclusion of cancer predisposition genes with a wide and variably penetrant phenotype when disrupted, on breast cancer gene panels, is a recognised challenge. Thus many commercial gene panels for breast cancer hereditary predisposition include, in addition to $T P 53$, the $C D H 1$ tumour suppressor gene. Whilst germline $\mathrm{CDH} 1$ mutations have been described in $0.34 \%$ of lobular breast cancer cases [22], they are more commonly associated with diffuse gastric cancer, a diagnosis with a dismal prognosis and prophylactic gastrectomy being the main preventable measure. In view of the uncertainties around true penetrance in breast cancer and the real potential for psychological harm, $\mathrm{CDHl}$ is not included in NHS England hereditary breast cancer panel testing, as was determined by the UK Cancer Genetics Group [23].

Similarly, is it therefore worthwhile including TP53 in gene panels for women at older ages? The potential benefits of the new surveillance protocols in early detection of future cancers and decision making to potentially avoid second cancers from radiotherapy [12] are clear, as well as the importance of reproductive decision making and offering testing to other potentially at risk family members. However, there are some potential serious harms that can be caused to women who do not have a definite pathogenic variant and potential psychological harm to the tiny proportion that do. Therefore a personalised and refined approach to diagnostic 
TP53 testing is needed, so that where a variant is detected, it is interpreted accurately and appropriate management put in place as required, with minimal distress.

\section{Interpreting TP53 variants}

There are two main concerns when interpreting variants discovered during germline TP53 testing in people with cancer

1. Is the variant detected the cause of the underlying cancer?

2. What is the allele frequency of the variant and is it confined to lymphocyte DNA?

\section{Pathogenicity of variants}

TP53 is not common for dominantly inherited cancer predisposing genes in that the majority of pathogenic variants are missense [5]. Therefore, complex analyses are required, unless there is already definitive evidence that the variant is pathogenic. Most pathogenic TP53 missense variants reside in the important DNA core binding domain equating to exons 4-8 where the original cases were found [1]. Most pathogenic missense variants act in a dominant negative fashion with protein products forming tetramers with wild type p53 [5]. Information that can help classify variants can be obtained from sources such as the IARC database (https:// p53.iarc.fr/) and for general population frequency estimates from the Genome Aggregation Database (gnomAD; https:// gnomad.broadinstitute.org/). It is critically important that missense variants should be classified by the widely used ACMG/AMP guidelines [24]. A subcommittee of which, has developed further guidance specific to TP53 [25]. The stringent clinical criteria are in place so that (together with strict functional criteria) missense variants from mass gene panel testing don't get over-called. These include:

1. Phenotype information (scores are given for fulfilling Classical LFS or the Chompret criteria, but not for single tumours outwith the criteria);

2. Functional analyses of variants using different in vitro assays performed either in yeast or cultured cells [2629].

Importantly at least two different functional tests that predict pathogenicity are required to score in that category [25]. The new ACMG/AMP criteria for germline TP53 variants classification are deliberately stringent to avoid mis-classification [25]. The importance of this has been demonstrated by the potential for 'over-classification' of TP53 variants resulting in as high as a frequency as 1 in 500 in gnomAD [30]. If a more stringent approach is used, this provides a more likely 1 in 5000 frequency [30-32]. The less parsimonious approaches to classification have resulted in colorectal cancer risk being almost certainly overestimated in LFS [12]; one report mis-classified five of the six germline reported variants as pathogenic $[12,33]$. Given that over age 46 potentially only $0.1-0.2 \%$ of women with breast cancer will have a pathogenic variant, there is an almost similar chance that some laboratories will over classify variants that are unlikely to be associated with high or even moderate cancer risk [30, 31].

\section{TP53 allele frequency}

Most molecular reports on germline testing from commercial laboratories did not include the allele frequency of the variant until recently (many still do not!). Providing these has become straightforward since moving from Sanger to Next Generation sequencing (NGS) where identification of low DNA allele frequencies has been substantially enhanced. This has been shown to be very valuable in identifying underlying mosaic variants in monogenic conditions such as NF2 [34]. However, there is a particular pitfall in TP53 testing as well as for a number of other genes such as PPM1D and several oncogenes. A frequent cause of low level allele frequencies detected is clonal haematopoiesis of indeterminate potential (CHIP) [35-39]. CHIP has recently become apparent in lymphocyte DNA panel testing by NGS. Older smokers or those who have had chemotherapy or radiotherapy treatments are particularly likely to manifest this. CHIP was first reported in patients over 70 years of age, but can be detected from 30 years of age. The frequency of CHIP increases with age, smoking and chemotherapy or radiotherapy treatments [35-39]. Even with an allele frequency consistent with a germline variant of 50\%, clonal haematopoiesis is still possible and should be considered where a TP53 variant is found in a context not usually associated with germline TP53 [36, 39]. The concern is that probably > $50 \%$ of TP53 variants found on panel testing are due to CHIP and therefore for those aged over 46 this is likely to be the predominant reason for identifying an apparently pathogenic TP53 variant at all. The presence of true mosaic TP53 alterations should be considered in patients with sporadic cancers strongly suggestive of a pathogenic TP53 variant, such as paediatric ACC, choroid plexus carcinoma, and breast cancer $\leq 30$ years, and patients with multiple TP53 core primary tumours [12]. However, the detection of a TP53 variants at significantly $<50 \%$ allele frequency on lymphocyte DNA NGS should prompt confirmation of the variant in the tumour and preferably another tissue without lymphocytes such as hair follicle or skin biopsy with fibroblast culture $[12,39]$. Where the variant is absent from the tumour (best tested on section without clear infiltration with lymphocytes/ macrophages) and other tissues, clonal haematopoiesis is 
by far the most likely cause (Fig. 1). Even in those with an apparent $50 \%$ allele frequency who do not meet LFS criteria, other tissues should be tested because, as many as 6/16 $(37.5 \%)$ tested in one study who were apparently heterozygote had no evidence of the variant in fibroblast culture [37].

\section{Breast cancer risks and overall penetrance}

That there is a very high risk of breast cancer aged $\leq 30$ years is clear from the high detection rates of TP53 pathogenic variants in women with breast cancer at this age. The BRIDGES study showed a 300 fold relative risk potentially equivalent to a $30 \%$ risk by the 31 st birthday using a $0.1 \%$ risk by age 30 for the population in the UK [40]. Even using a $2 \%$ detection frequency from the lowest detection rate studies, this would equate to a 100 -fold relative risk and a $10 \%$ cumulative risk [17]; the $5 \%$ rate $[5,9]$ would therefore equate to a $25 \%$ risk similar to that estimated from cohorts [41]. What is also clear is that this relative risk drops off fairly dramatically after 30 years of age with detection rates in commercial testing of $0.71 \%$ for TP53 in 4344 samples aged $31-36$, and $0.24 \%$ in over 20,000 samples aged $37-46$ (https://www.ambrygen.com/providers/resources/prevalence -tool, accessed 28/08/2020, [21]). Whilst, this might still represent relative risks of 10 -fold for that latter period this is now less than would be expected for BRCA1. No reliable cumulative risks are available from large-scale prospective studies and cohort studies that include retrospectively ascertained cases probably exaggerate the lifetime penetrance estimated at around $90 \%$ in one study [41]. After age 45 it is not impossible that risks are little different to population risks; in Manchester we have seen no prospective breast cancers in women over 34 years of age with 6/9 occurring aged $\leq 30$. Indeed in 15 female TP53 carriers with 83 years of follow up post pathogenic variant report aged $>45$ years no breast cancers have been observed.

There is clearly also a very high rate of contralateral breast cancer approaching 4-7\% per annum which was significantly higher than for $B R C A 1$ or $B R C A 2$ in those diagnosed aged $<35$ [42]. This remained true in prospective analysis and should justify a discussion of risk reducing contralateral mastectomy as long as survival chances are good from the first primary.

The overall cumulative all cancer incidence of germline pathogenic variants in TP53 from familial cases has been estimated at $73-100 \%$ by age 70 , with risks close to $100 \%$ in women [41, 43-45]. It is highly likely nonetheless that penetrance is variable. This may be explained in some part by the dominant-negative effects of most pathogenic missense variants. These TP53 dominant-negative missense variants are usually found in families with childhood malignancies and are

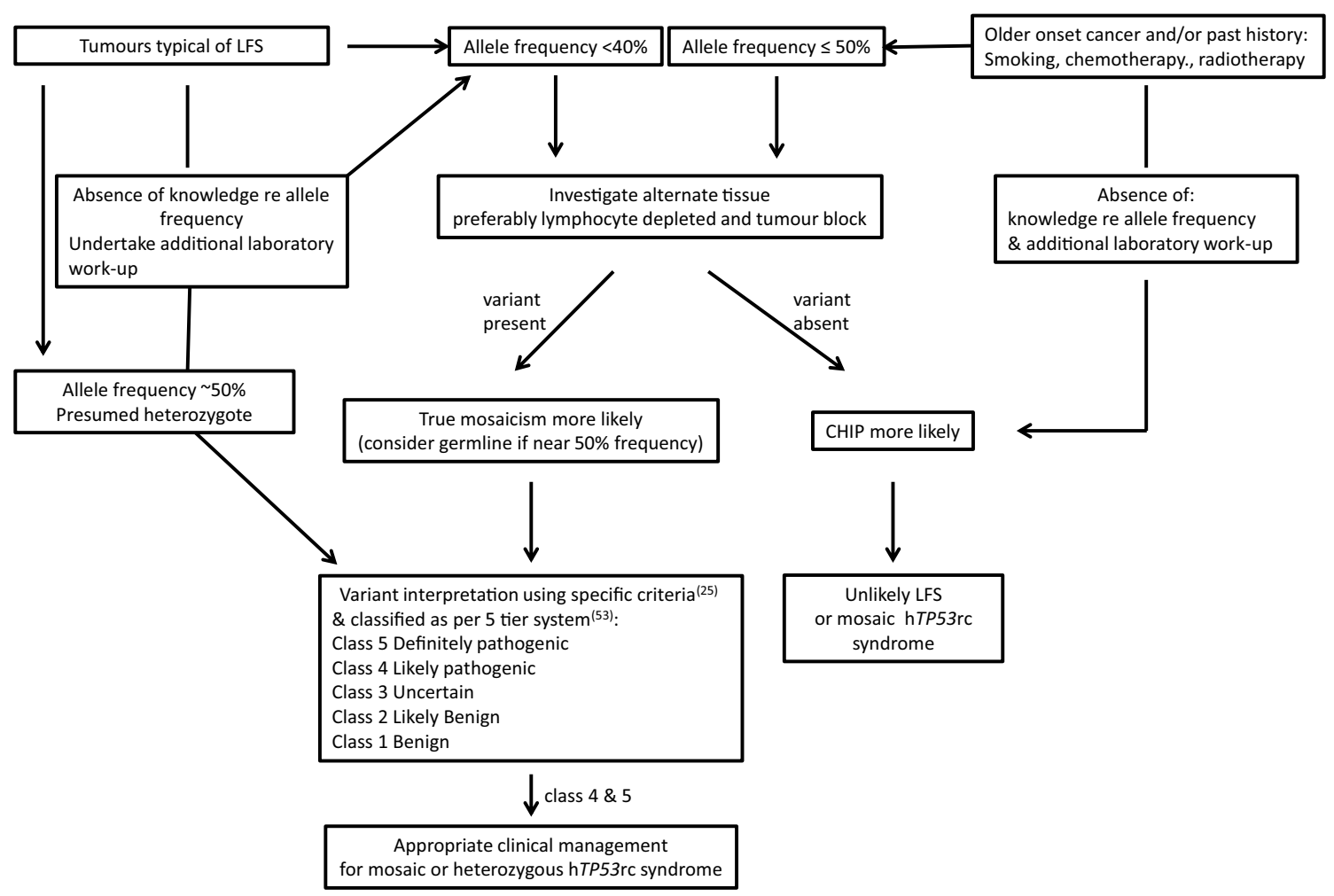

Fig. 1 Flow-chart to aid in distinguishing mosaicism from CHIP and subsequent variant interpretation 
Table 2 Recommendations for TP53 testing in women with breast cancer [11]

\begin{tabular}{lll}
\hline A) When testing is definitely recommended & (B) When testing could be considered & (C) When NOT to test TP53 \\
\hline $\begin{array}{l}\text { Women with invasive breast cancer or DCIS } \leq \\
30\end{array}$ & $\begin{array}{l}\text { Women with breast cancer } \leq 46 \text { not fulfill- } \\
\text { ing Chompret criteria or other criteria in }\end{array}$ & $\begin{array}{c}\text { Breast cancer aged }>46 \text { with no fulfilment of } \\
\text { Chompret criteria and no previous malig- } \\
\text { nancy or DCIS }\end{array}$
\end{tabular}

Women with breast cancer $\leq 46$ fulfilling Chom-

pret criteria

generally highly penetrant $[5,46]$. In contrast, typical loss of function variants (frameshift or nonsense variants, splicing variants, large genomic rearrangements, and non-dominantnegative missense variants), are predominantly identified in families with mainly adult onset cancers and are likely to have a lower overall cancer penetrance [5, 12, 44]. A particularly important example of such a low penetrance, but still pathogenic variant, is the non-dominant-negative missense p.Arg337His variant, present in $0.3 \%$ of the Southern Brazilian population [45-49]. Nevertheless this variant is definitely associated with breast cancer risk [48, 49], but its overall penetrance for breast cancer is still to be determined.

\section{Risks from standard breast cancer therapies in TP53 carriers}

There is a very high likelihood of subsequent primary tumours in patients with pathogenic TP53 variants [5, 44]. This appears to occur in $>40 \%$ of TP53 carriers despite often poor survival from the first primary [5, 44]. Radiotherapy particularly, but also some types of chemotherapy, appear to increase this metachronous primary cancer risk with a particular risk within the radiation field $[5,12,50]$. Studies of chemotherapy/radiotherapy effects on lymphocytes with wild-type or mutant TP53 and on TP53 mouse models appears to provide additional evidence for this risk [51]. Therefore, for women with a significant likelihood of a germline TP53 related breast cancer, testing for pathogenic variants should ideally be performed prior to commencing treatment [12]. If a pathogenic TP53 variant is found particularly in young women with good survival chances mastectomy should be undertaken rather than breast conserving surgery and radiotherapy as per recent guidance [12]. In these young women with high contralateral risk the option of bilateral mastectomy should also be discussed [12, 42].

\section{Effects of germline TP53 pathogenic variant on psychological distress}

There is not a great deal published on the impact of TP53 testing on psychological factors. However, there are overall higher levels of distress in families with TP53 pathogenic variants even in those testing negative [52]. More research is needed in this area particularly on the impact of an unexpected TP53 test result from panel testing as in our experience identifying a TP53 variant is often associated with high levels of anxiety.

\section{Breast cancer testing criteria for TP53}

Women with breast cancer $>46$ years of age have a very low likelihood of a germline pathogenic variant in the absence of Chompret criteria [12]. As described above, this is probably only around $0.1 \%$. These women are probably more likely to have a CHIP diagnosis which will require fibroblast culture and/or obtaining tissue block material. They are also at least as likely to have a variant of uncertain significance that might be considered as 'hot' [27]. This does not even take into account the many variants that would still be considered class 3 [53]. The recent guidance recommends that breast cancer patients $>46$ years at diagnosis should NOT be tested for TP53 [12]. Given the above this seems a sensible approach as the dis-benefits of testing and potential huge anxieties around whether there is variant misclassification, CHIP or the waiting game around a 'hot' class 3 that probably will never be classified as high risk are considerably higher than a meaningful result. There are clear recommendations for testing aged $\leq 30$ and with Chompret criteria [12], but this leaves many women with breast cancers aged 31-46 with no clear guidance where testing might be considered (Table 2) albeit still with a low likelihood of detection $(\sim 0.33 \%)$. National testing panels for breast cancer in the UK now only include $B R C A 1, B R C A 2$ and PALB2 and given the above it would seem appropriate to have breast panels for older women with breast cancer that also exclude TP53. Website: The complete ERN guidelines can be uploaded from the ERN website: https://www.genturis.eu [12].

Acknowledgements DGE and ERW are supported by the Manchester NIHR Biomedical Research Centre (IS-BRC-1215-20007).

\section{Compliance with ethical standards}

Conflict of interest DGE has received travel grants from AstraZeneca. 


\section{References}

1. Malkin D, Li FP, Strong LC, Fraumeni JF Jr, Nelson CE, Kim DH et al (1990) Germ line p53 mutations in a familial syndrome of breast cancer, sarcomas, and other neoplasms. Science 250:1233-1238

2. Li FP, Fraumeni JF Jr (1969) Soft-tissue sarcomas, breast cancer, and other neoplasms. A familial syndrome? Ann Intern Med 71:747-752

3. Lynch HT, Guirgis HA (1979) Childhood cancer and the SBLA syndrome. Med Hypotheses 5:15-22

4. Li FP, Fraumeni JF, Mulvihill JJ, Blattner WA, Dreyfus MG, Tucker MA, Miller RW (1988) A cancer family syndrome in twenty-four kindreds. Cancer Res 48:5358-5362

5. Bougeard G, Renaux-Petel M, Flaman JM, Charbonnier C, Fermey P, Belotti M, Gauthier-Villars M, Stoppa-Lyonnet D, Consolino E, Brugieres L, Caron O, Benusiglio PR, Bressac-de Paillerets B, Bonadona V, Bonaiti-Pellie C, Tinat J, Baert-Desurmont S, Frebourg T (2015) Revisiting li-fraumeni syndrome from TP53 mutation carriers. J Clin Oncol 33(21):2345-2352. https://doi. org/10.1200/JCO.2014.59.5728

6. Magnusson S, Gisselsson D, Wiebe T, Kristoffersson U, Borg A, Olsson H (2012) Prevalence of germline TP53 mutations and history of Li-Fraumeni syndrome in families with childhood adrenocortical tumors, choroid plexus tumors, and rhabdomyosarcoma: a population-based survey. Pediatr Blood Cancer 59:846-853

7. Hettmer S, Archer NM, Somers GR, Novokmet A, Wagers AJ, Diller L et al (2014) Anaplastic rhabdomyosarcoma in TP53 germline mutation carriers. Cancer 120:1068-1075

8. Tabori U, Shlien A, Baskin B, Levitt S, Ray P, Alon N et al (2010) TP53 alterations determine clinical subgroups and survival of patients with choroid plexus tumors. J Clin Oncol 28:1995-2001

9. Evans DG, Moran A, Hartley R, Dawson J, Bulman B, Knox F, Howell A, Lalloo F (2010) Long-term outcomes of breast cancer in women aged 30 years or younger, based on family history, pathology and BRCA1/BRCA2/TP53 status. Br J Cancer 102:1091-1098

10. Gonzalez KD, Noltner KA, Buzin CH, Gu D, Wen-Fong CY, Nguyen VQ et al (2009) Beyond li fraumeni syndrome: clinical characteristics of families with p53 germline mutations. J Clin Oncol 27:1250-1256

11. Ruijs MW, Verhoef S, Rookus MA, Pruntel R, van der Hout AH, Hogervorst FB et al (2010) TP53 germline mutation testing in 180 families suspected of Li-Fraumeni syndrome: mutation detection rate and relative frequency of cancers in different familial phenotypes. J Med Genet 47:421-428

12. Frebourg T, Bajalica Lagercrantz S, Oliveira C, Magenheim R, Evans DG, European Reference Network GENTURIS (2020) Guidelines for the Li-Fraumeni and heritable TP53-related cancer syndromes. Eur J Hum Genet. https://doi.org/10.1038/s4143 1-020-0638-4

13. Hanson H, Brady AF, Crawford G, Eeles RA, Gibson S, Jorgensen M, Izatt L, Sohaib A, Tischkowitz M, Evans DG, Consensus Group Members (2020) UKCGG Consensus Group guidelines for the management of patients with constitutional TP53 pathogenic variants. J Med Genet. https://doi.org/10.1136/jmedgenet-2020106876

14. Kratz CP, Achatz MI, Brugières L, Frebourg T, Garber JE, Greer $\mathrm{MC}$ et al (2018) Cancer screening recommendations for individuals with li-fraumeni syndrome. Clin Cancer Res 23:e38-e45

15. Villani A, Shore A, Wasserman JD, Stephens D, Kim RH, Druker $\mathrm{H}$ et al (2016) Biochemical and imaging surveillance in germline TP53 mutation carriers with Li-Fraumeni syndrome: 11 year follow-up of a prospective observational study. Lancet Oncol 17:1295-1305
16. Fortuno C, James PA, Spurdle AB (2018) Current review of TP53 pathogenic germline variants in breast cancer patients outside Li-Fraumeni syndrome. Hum Mutat 39:1764-1773

17. Bakhuizen JJ, Hogervorst FB, Velthuizen ME, Ruijs MW, van Engelen K, van Os TA, Gille JJ, Collée M, van den Ouweland AM, van Asperen CJ, Kets CM, Mensenkamp AR, Leter EM, Blok MJ, de Jong MM, Ausems MG (2019) TP53 germline mutation testing in early-onset breast cancer: findings from a nationwide cohort. Fam Cancer 18:273-280

18. Sidransky D, Tokino T, Helzlsouer K, Zehnbauer B, Rausch G, Shelton B, Prestigiacomo L, Vogelstein B, Davidson N (1992) Inherited p53 gene mutations in breast cancer. Cancer Res 52:2984-2986

19. Zelada-Hedman M, Børresen-Dale AL, Claro A, Chen J, Skoog L, Lindblom A (1997) Screening for TP53 mutations in patients and tumours from 109 Swedish breast cancer families. Br J Cancer 75:1201-1204

20. Dorling L, Carvalho S, Allen J, González-Neira A, Luccarini C, Wahlström C, Pooley KA, Parsons MT, Fortuno CL (2020) Breast cancer risk genes: association analysis of rare coding variants in 34 genes in 60,466 cases and 53,461 controls. N Engl $\mathrm{J}$ Med. In press

21. Hart SN, Polley EC, Yussuf A, Yadav S, Goldgar DE, Hu C, LaDuca H, Smith LP, Fujimoto J, Li S, Couch FJ, Dolinsky JS (2020) Mutation prevalence tables for hereditary cancer derived from multigene panel testing. Hum Mutat 41:e1-e6. https://doi. org/10.1002/humu.24053

22. Petridis C, Arora I, Shah V, Moss CL, Mera A, Clifford A, Gillett C, Pinder SE, Tomlinson I, Roylance R, Simpson MA, Sawyer EJ (2019) Frequency of pathogenic germline variants in CDH1, BRCA2, CHEK2, PALB2, BRCA1, and TP53 in sporadic lobular breast cancer. Cancer Epidemiol Biomarkers Prev 28:1162-1168

23. Taylor A, Brady AF, Frayling IM, Hanson H, Tischkowitz M, Turnbull C, Side L, UK Cancer Genetics Group (UK-CGG) (2018) Consensus for genes to be included on cancer panel tests offered by UK genetics services: guidelines of the UK Cancer Genetics Group. J Med Genet 55:372-377

24. Richards S, Aziz N, Bale S, Bick D, Das S, Gastier-Foster J, Grody WW, Hegde M, Lyon E, Spector E, Voelkerding K, Rehm HL (2015) ACMG Laboratory Quality Assurance Committee (2015) Standards and guidelines for the interpretation of sequence variants: a joint consensus recommendation of the American College of Medical Genetics and Genomics and the Association for Molecular Pathology. Genet Med. 17:405-424

25. Fortuno C, Lee K, Olivier M, Pesaran T, Mai PL, de Andrade KC et al (2020) Specifications of the ACMG/AMP variant interpretation guidelines for germline TP53 variants. Hum Mutat in press

26. Kato S, Han SY, Liu W, Otsuka K, Shibata H, Kanamaru R, Ishioka C (2003) Understanding the function-structure and functionmutation relationships of $\mathrm{p} 53$ tumor suppressor protein byhighresolution missense mutation analysis. Proc Natl Acad Sci USA 100:8424-8429

27. Zerdoumi Y, Lanos R, Raad S, Flaman JM, Bougeard G, Frebourg T, Tournier I (2017) Germline TP53 mutations result into a constitutive defect of p53 DNA binding and transcriptional response to DNA damage. Hum Mol Genet 26:2591-2602

28. Giacomelli AO, Yang X, Lintner RE, McFarland JM, Duby M, Kim J et al (2018) Mutational processes shape the landscape of TP53 mutations in human cancer. Nat Genet 50:1381-1387

29. Kotler E, Shani O, Goldfeld G, Lotan-Pompan M, Tarcic O, Gershoni A et al (2018) A systematic p53 mutation library links differential functional impact to cancer mutation pattern and evolutionary conservation. Mol Cell 71:178-90

30. de Andrade KC, Frone MN, Wegman-Ostrosky T, Khincha PP, Kim J, Amadou A et al (2019) Variable population prevalence 
estimates of germline TP53 variants: a gnomAD-based analysis. Hum Mutat 40:97-105

31. Evans DG, Turnbull C, Woodward ER (2019) Concern regarding classification of germline TP53 variants as likely pathogenic. Hum Mutat 40:828-831

32. Lalloo F, Varley J, Ellis D, Moran A, O'Dair L, Pharoah P, Evans D, Onset Breast Cancer Study Group (2003) Prediction of pathogenic mutations in patients with early-onset breast cancer by family history. Lancet 361:1101-1102

33. Yurgelun MB, Masciari S, Joshi VA, Mercado RC, Lindor NM et al (2015) Germline TP53 mutations in patients with early-onset colorectal cancer in the colon cancer family registry. JAMA Oncol $1: 214-221$

34. Evans DG, Hartley CL, Smith PT, King AT, Bowers NL, Tobi S, Wallace AJ, Perry M, Anup R, Lloyd SKW, Rutherford SA, Hammerbeck-Ward C, Pathmanaban ON, Stapleton E, Freeman SR, Kellett M, Halliday D, Parry A, Gair JJ, Axon P, Laitt R, Thomas O, Afridi SK, Obholzer R, English Specialist NF research group, Duff C, Stivaros SM, Vassallo G, Harkness EF, Smith MJ (2020) Incidence of mosaicism in 1055 de novo NF2 cases: much higher than previous estimates with high utility of next-generation sequencing. Genet Med 22:53-59

35. Batalini F, Peacock EG, Stobie L, Robertson A, Garber J, Weitzel JN, Tung NM (2019) Li-Fraumeni syndrome: not a straightforward diagnosis anymore-the interpretation of pathogenic variants of low allele frequency and the differences between germline PVs, mosaicism, and clonal hematopoiesis. Breast Cancer Res 21:107

36. Weber-Lassalle K, Harter P, Hauke J, Ernst C, Kommoss S, Marmé F et al (2018) Diagnosis of li-fraumeni syndrome: differentiating TP53 germline mutations from clonal hematopoiesis: results of the observational AGO-TR1 trial. Hum Mutat 39:2040-2046

37. Weitzel JN, Chao EC, Nehoray B, Van Tongeren LR, LaDuca H, Blazer KR et al (2018) Somatic TP53 variants frequently confound germ-line testing results. Genet Med 20:809-816

38. Chen S, Liu Y (2019) p53 involvement in clonal hematopoiesis of indeterminate potential. Curr Opin Hematol 4:235-240

39. Mester JL, Jackson SA, Postula K, Stettner A, Solomon S, Bissonnette J, Murphy PD, Klein RT, Hruska KS (2020) Apparently heterozygous TP53 pathogenic variants may be blood limited in patients undergoing hereditary cancer panel testing. J Mol Diagn 22:396-404

40. https://www.cancerresearchuk.org/health-professional/cance r-statistics/statistics-by-cancer-type/breast-cancer/incidence-invas ive\#heading-One Accessed 28 Aug 2020

41. Shin SJ, Dodd-Eaton EB, Peng G, Bojadzieva J, Chen J, Amos CI et al (2020) Penetrance of different cancer types in families with Li-Fraumeni syndrome: a validation study using multi-center cohorts. Cancer Res 80:354-360

42. Hyder Z, Harkness EF, Woodward ER, Bowers NL, Pereira M, Wallace AJ, Howell SJ, Howell A, Lalloo F, Newman WG, Smith MJ, Evans DG (2020) Risk of contralateral breast cancer in women with and without pathogenic variants in BRCA1, BRCA2, and tp53 genes in women with very early-onset ( $<36$ Years) breast cancer. Cancers (Basel) 12:378
43. Chompret A, Brugières L, Ronsin M, Gardes M, Dessarps-Freichey F, Abel A et al (2000) P53 germline mutations in childhood cancers and cancer risk for carrier individuals. Br J Cancer 82:1932-1937

44. Mai PL, Best AF, Peters JA, DeCastro RM, Khincha PP, Loud JT et al (2016) Risks of first and subsequent cancers among TP53 mutation carriers in the National Cancer Institute Li-Fraumeni syndrome cohort. Cancer 122:3673-3681

45. Amadou A, Waddington Achatz MI, Hainaut P (2018) Revisiting tumor patterns and penetrance in germline TP53 mutation carriers: temporal phases of Li-Fraumeni syndrome. Curr Opin Oncol 30:23-29

46. Figueiredo BC, Sandrini R, Zambetti GP, Pereira RM, Cheng C, Liu W et al (2006) Penetrance of adrenocortical tumours associated with the germline TP53 R337H mutation. J Med Genet 43:91-96

47. Achatz MI, Olivier M, Le Calvez F, Martel-Planche G, Lopes A, Rossi BM et al (2007) The TP53 mutation, R337H, is associated with Li-Fraumeni and Li-Fraumeni-like syndromes in Brazilian families. Cancer Lett 245:96-102

48. Palmero EI, Schüler-Faccini L, Caleffi M, Achatz MI, Olivier M, Martel-Planche G et al (2008) Detection of R337H, a germline TP53 mutation predisposing to multiple cancers, in asymptomatic women participating in a breast cancer screening program in Southern Brazil. Cancer Lett 261:21-25

49. Andrade KC, Santiago KM, Fortes FP, Mambelli LI, Nóbrega AF, Achatz MI (2016) Early-onset breast cancer patients in the South and Southeast of Brazil should be tested for the TP53 p. R337H mutation. Genet Mol Biol 39:199-202

50. Kasper E, Angot E, Colasse E, Nicol L, Sabourin JC, Adriouch $S$ et al (2018) Contribution of genotoxic anticancer treatments to the development of multiple primary tumours in the context of germline TP53 mutations. Eur J Cancer 101:254-262

51. Evans DG, Birch JM, Ramsden RT, Sharif S, Baser ME (2006) Malignant transformation and new primary tumours after therapeutic radiation for benign disease: substantial risks in certain tumour prone syndromes. J Med Genet 43:289-294

52. Lammens CR, Aaronson NK, Wagner A, Sijmons RH, Ausems MG, Vriends AH, Ruijs MW, van Os TA, Spruijt L, Gómez García EB, Kluijt I, Nagtegaal T, Verhoef S, Bleiker EM (2010) Genetic testing in Li-Fraumeni syndrome: uptake and psychosocial consequences. J Clin Oncol 28(18):3008-3014

53. Plon SE, Eccles DM, Easton D, Foulkes WD, Genuardi M, Greenblatt MS, Hogervorst FB, Hoogerbrugge N, Spurdle AB, Tavtigian SV, IARC Unclassified Genetic Variants Working Group (2008) Sequence variant classification and reporting: recommendations for improving the interpretation of cancer susceptibility genetic test results. Hum Mutat 29:1282-1291

Publisher's Note Springer Nature remains neutral with regard to jurisdictional claims in published maps and institutional affiliations. 